\title{
Coulisses
}

Revue de théâtre

14 | Printemps 1996

Varia

\section{Présentation du spectacle en huit tableaux}

\section{Vadim Golikov}

Traducteur: Jacques Prebet

\section{CpenEdition}

\section{Journals}

Édition électronique

URL : http://journals.openedition.org/coulisses/4579

DOI : $10.4000 /$ coulisses.4579

ISSN : 2546-9460

\section{Éditeur}

Presses universitaires de Franche-Comté

\section{Édition imprimée}

Date de publication : 1 mai 1996

Pagination : 35-36

ISSN : 1150-594X

\section{Référence électronique}

Vadim Golikov, "Présentation du spectacle en huit tableaux », Coulisses [En ligne], 14 | Printemps 1996, mis en ligne le 20 mars 2019, consulté le 24 octobre 2019. URL : http://journals.openedition.org/ coulisses/4579; DOI : 10.4000/coulisses.4579

Ce document a été généré automatiquement le 24 octobre 2019

Coulisses 


\title{
Présentation du spectacle en huit tableaux
}

\author{
Vadim Golikov
}

Traduction : Jacques Prebet

\section{Premier acte de La Mouette. Le spectacle de Treplev}

Derniers préparatifs. Les spectateurs prennent place. L'héroïne n'est toujours pas là ! Mais la voici. On commence. "Les hommes, les lions, les aigles, les perdrix... ». Le metteur en scène est nerveux : sans lui en parler, l'actrice s'est mis en tête de jouer chacun de ces animaux. Les spectateurs ne réagissent pas comme il l'aurait voulu... sa mère surtout ! Il interrompt le spectacle !

\section{D'après la nouvelle de Tcheckhonte ${ }^{1}$ Deux scandales}

2 Un jeune chef d'orchestre plein de talent est en répétition. La cantatrice, qui est amoureuse de lui, chante faux. Il est furieux. Il lui arrache la partition et la chasse. Elle tombe malade, ses camarades lui rendent visite. Le chef d'orchestre s'excuse. Les acteurs, pour prévenir un nouveau scandale, le font boire. Le vin le rend bon et conciliant. Il tombe amoureux de la cantatrice, ils ne se séparent pas l'un de l'autre une semaine entière. Finalement, lassé, le maestro revient diriger. Et à nouveau l'actrice chante faux! Il la chasse définitivement, du théâtre et du chœur! Par un temps de tempête elle part dans le néant. Quelques années s'écoulent. Dans une autre ville, le maestro remplace au pied levé un collègue malade. On donne Faust de Gounod. Le chef d'orchestre est charmé par une cantatrice en qui il reconnait son amour d'autrefois. Il laisse là son rôle de chef d'orchestre et bondit sur la scène. Mais il est accueilli par un soufflet, vengeance pour le passé et le présent. Il est au désespoir, il a trahi Gounod, il a gâché le spectacle où se produisait une grande cantatrice. 


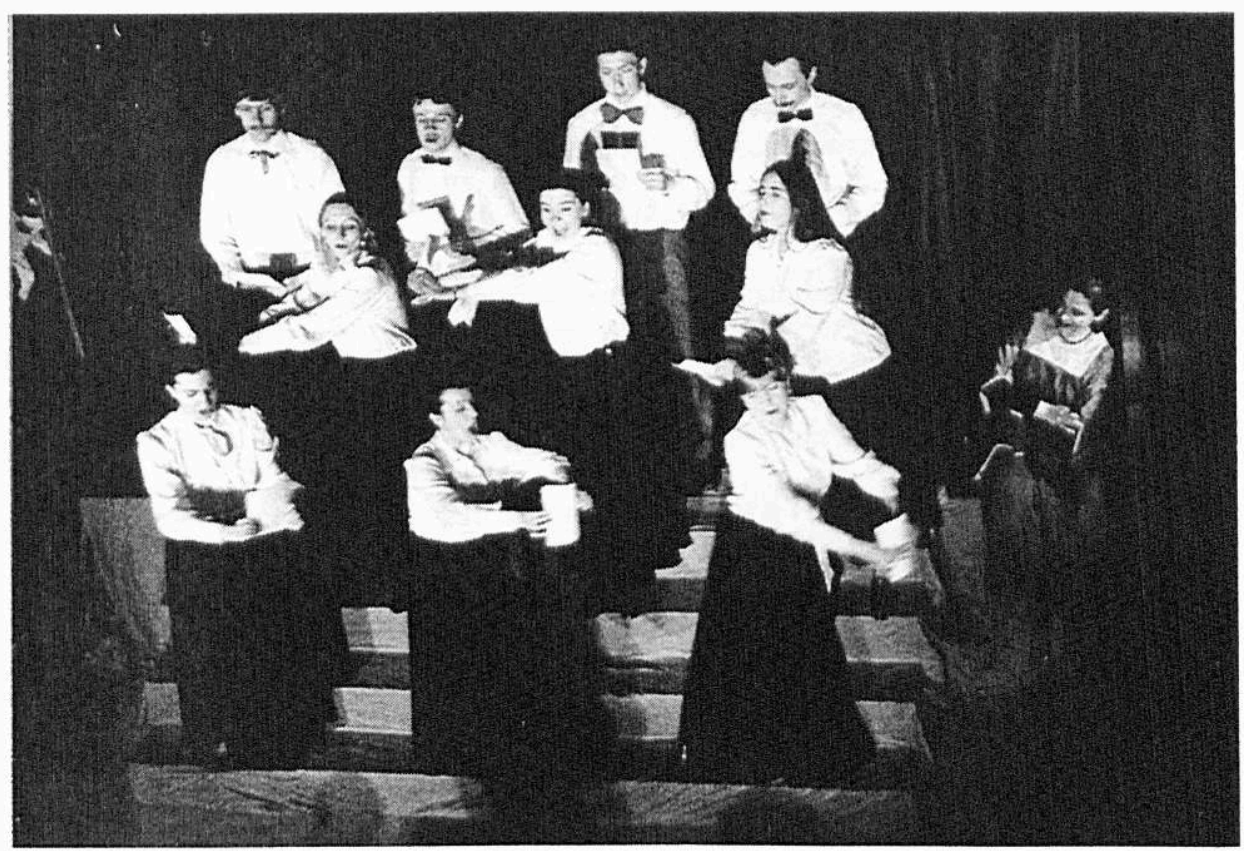

\section{Deuxième acte de La Mouette. Le rendez-vous de Nina et Trigorine}

Nina cherche à rencontrer le célèbre écrivain. Elle le trouve en train de pêcher. Arrive Treplev qui lui reproche de l'abandonner. Il jette à ses pieds une tasse qu'il a cassée. Voyant arriver Trigorine, il se retire. Nina reste seule avec son idole. Trigorine fait le modeste. Mais les manières directes et l'enthousiasme de Nina font leur effet sur lui. Malgré la brièveté de la rencontre, leur avenir est tracé.

\section{D'après L'impresario sur le divan (Tchekhonte)}

4 Un théâtre de province. Dans les coulisses se montre quelqu'un qui pourrait bien être ce Pryndine auquel l'impresario de la troupe doit beaucoup d'argent. Celui-ci se glisse sous un divan, dans la loge d'une actrice. Elle le découvre quand elle vient se changer. Voyant son double il la supplie de ne pas ébruiter la chose et lui promet une augmentation de son cachet. Elle accepte et repart sur la scène où l'appelle son rôle. Entre-temps, l'imprésario comprend son erreur (l'inconnu n'était pas Pryndine) et c'est en riant qu'il raconte tout à l'actrice revenue dans sa loge après un triomphe. Plus question d'augmentation. Dépitée, humiliée, l'actrice sanglote. 


\section{La Mouette, fin du quatrième acte}

5 Les années ont passé depuis le spectacle raté de Treplev. Le temps et la vie ont changé les gens (c'est pourquoi les mêmes personnages sont joués par d'autres acteurs). Treplev publie ses œuvres. Nina est devenue une actrice. Elle a eu de Trigorine un enfant qui est mort. Treplev l'aime comme autrefois. Mais, hélas, elle aime toujours Trigorine. Ce dernier est arrivé la veille dans sa propriété avec sa vieille maîtresse Arkadina. Nina désire le voir et se méprise pour cela. Epuisée moralement et physiquement (il fait un temps affreux) elle rôde autour de la maison sans se résoudre à y entrer. "Je suis une mouette! » répète-t-elle constamment. Treplev découvre la présence de Nina. Il est heureux qu'elle lui soit revenue, lui qui ne peut vivre sans elle, ni écrire. Mais non, elle ne peut rester avec lui; elle a un engagement auprès d'un théâtre d'une petite ville. Il peut y partir avec elle! Non, elle refuse. Il finit par comprendre pourquoi elle est ici. Tous les rêves de Treplev s'écroulent. Nina lutte avec elle-même pour ne pas entrer dans la pièce où est Trigorine. Elle arrive à se forcer à partir. Avant de le faire, elle évoque ce jour proche et lointain, le jour de leur spectacle, les premiers mots du monologue lui reviennent : « les hommes, les lions, les aigles, les perdrix... ». Elle s'enfuit en sanglotant. Treplev prend son fusil et se tire une balle dans la tête dans la pièce voisine.

\section{D'après Le Portefeuille (Tchekhonte)}

6 Trois acteurs désargentés vont d'une ville à une autre en marchant le long d'une voie ferrée. Soudain, un portefeuille avec de l'argent! Joie sans bornes. On envoie le plus jeune dans le plus proche village chercher de quoi manger et boire. Tout en marchant il décide d'empoisonner ses compagnons : de toutes façons, ce sont de mauvais acteurs, et avec l'argent il ouvrira son propre théâtre! Les autres, en l'attendant, ont la même idée : ils décident de le tuer. Ce qu'ils font, après quoi ils boivent la vodka empoisonnée par ses soins et meurent dans d'atroces souffrances. En route pour l'au-delà, leurs âmes qui s'envoient des baisers nous conseillent de ne pas trop croire aux déclarations d'amour des acteurs.

\section{Etude dramatique Le Chant du cygne. Calchas}

7 Un vieil acteur comique, après une représentation donnée en son honneur, se réveille dans le théâtre vide. Il porte encore le costume du pontife Calchas (on vient déjouer $L a$ Belle Hélène d'Offenbach). Il est ivre. Il a peur tout seul, il voudrait voir un être vivant. Il se retrouve sur la scène et il regarde la salle sombre. Il comprend que dans sa vie il n'y a rien eu d'autre que ce trou obscur. Et qu'il n'y aura rien d'autre ; sa vie est derrière lui. Une silhouette apparait, qu'il prend pour un habitant de l'au-delà. Mais non, ce n'est que le souffleur, qui habite dans le théâtre.

Le vieil homme commence sa confession : solitude et vie inutile. Il y a longtemps, il a aimé quelqu'un, il a demandé la main d'une jeune fille : en échange elle a exigé qu'il cesse d'être acteur. Cela a fait de lui un cynique. Il est devenu un acteur comique étouffant en lui son talent dramatique. Il se rappelle tous les rôles qu'il n'a pas joués : le 
roi Lear, Hamlet, Othello. L'art fait revivre le vieux comédien. Et si l'art existe, alors la mort n'existe pas!

\section{Récit de Tchekhonte Une découverte}

Un fonctionnaire plus tout jeune croise dans la foule son amour de jeunesse. C'est une vieille femme maintenant. En pensant à elle, il dessine le portrait de ce qu'elle était jadis. Le résultat est très évocateur. Il poursuit, poursuit encore et comprend qu'il aurait pu être un véritable artiste! Mentalement il peint divers tableaux (représentés par les acteurs). Il se prend à rêver à une carrière artistique. Mais son expérience lui dit que cette carrière n'est pas sûre. La satiété, l'aisance d'une vie entière sont les plus fortes. Il se calme et s'endort. A la question posée par le titre du spectacle, sa réponse est négative.

\section{NOTES}

1. Tchekhonte : un des noms de plume de Tchekhov. 